\title{
Assessment of Plant Species Diversity at Pasir Tengkorak Forest Reserve, Langkawi Island, Malaysia
}

\author{
M.S. Abdul Hayat, Kamziah Abd Kudus (Corresponding author) \\ I. Faridah-Hanum, A.G. Awang Noor \& M.Nazre \\ Faculty of Forestry, University Putra Malaysia \\ 43400 Serdang, Selangor, Malaysia \\ Tel: 60-3-8946-7169Ｅ-mail: kamziah@putra.upm.edu.my
}

The research is financed by Research University Grant Scheme, Universiti Putra Malaysia (91037)

\begin{abstract}
Plant species diversity of a logged-over coastal forest within the Pasir Tengkorak Forest Reserve, Langkawi Island, Malaysia was assessed by establishing a 1-ha plot. All plants above $1.0 \mathrm{~cm}$ dbh (diameter of a tree at breast height), or 4.5 feet above ground level, the accepted point of diameter measurement for most trees were enumerated. Species diversity was defined as a combination of species richness and evenness. The jackknife estimate and species-area curve were applied to estimate the species richness. It was estimated using Simpson's index of diversity, Shannon-Weiner function and Brillouin index. Simpson's measure of evenness, Camargo's index of evenness and Smith and Wilson's index of evenness were also used to estimate species evenness. A total of 3414 individual trees representing 120 species, 81 genera and 31 families were recorded. Species with highest relative abundance were Swintonia sp1 (0.12), Garcinia eugnifolia (0.09) and Syzygium sp1 (0.05). The jackknife estimate of species richness was 132.9 and the regress ion equation to estimate species richness was $\operatorname{Ln} \hat{S}=2.53+0.24 \ln (A)$ with $r^{2}=96.0 \%$. Species diversity was high with Simpson's index of diversity with a value of 0.96 , while Shannon-Weiner index was 5.42 and Brillouin's Index was 5.14. However, Simpson's measure of evenness, Camargo's index of evenness and Smith and Wilson's index of evenness were $0.264,0.378$, and 0.419 , respectively. Results indicated that species richness and species diversity were high, but evenness was low in this logged-over coastal forest.
\end{abstract}

Keywords: Coastal forest, Species richness, Diversity, Evenness

\section{Introduction}

Langkawi is located in the northern west coast of Peninsular Malaysia, bordering the south of Thailand -off the coast of Kedah and is made up of 99 islands when the tide is high and 104 islands when the tide is low. The largest of the islands is Pulau Langkawi with an area of about $478.5 \mathrm{sq} \mathrm{km}$. The present study was conducted at Compartment 2, Machinchang Forest Reserve also known as Pasir Tengkorak Forest Reserve, Langkawi Island, Malaysia. Pasir Tengkorak Forest Reserve is a coastal forest with elevation not more than $300 \mathrm{~m}$ a.s.l and located $40 \mathrm{~km}$ from Pekan Kuah, Langkawi and has been promoted as recreational forest and ecotourism destination.

Generally, tropical forests are known to have high species diversity. In Malaysia, biological diversity research has been carried out to assess species richness, diversity, similarity of various forest ecosystems (e.g. Faridah Hanum et al., 2001a and 2001b, and Rusea et al., 2001). This study was, therefore designed to explain variation in composition and diversity components of tree species in a 1-ha plot at Pasir Tengkorak Forest Reserve, Langkawi Island, Malaysia. Several statistical approaches were adopted as suggested by Krebbs (1999) to study species richness, species diversity, species similarity and species accumulation.

\section{Materials and methods}

\subsection{Study area}

The present study was conducted at Compartment 2, Machinchang Forest Reserve, Langkawi Island, Malaysia. Initial observation reveals that the forests show a predominance of species associated with the Indo-Burmese mainland and it is considerably due to altitude, soil and rock type. A 1-ha plot (i.e. $100 \mathrm{~m} \times 100 \mathrm{~m}$ ) was established at the elevation $130 \mathrm{~m}$ a.s.l. within the Pasir Tengkorak Forest Reserve. The 1-ha plot was divided into 100 quadrats of $10 \mathrm{~m} \times 10 \mathrm{~m}$ each. 


\subsection{Methods}

In each quadrate, data were gathered from trees and shrubs with diameter at breast height (dbh) of $1.0 \mathrm{~cm}$ and above. Other parameters recorded were species name and height. Data collected were classified and analyzed to calculate species richness, species diversity, similarity and rank abundance. The species richness estimators were computed based on the Jackknife method, species diversity index were calculated using Simpson's Index, Shannon-Wiener Index and Brillouin's Index. The evenness indexes were measured by Simpson's measure of evenness, Camargo's index of evenness and Smith and Wilson's index of evenness. Density, frequency, basal area and their relative values and importance value index (IVI) of the tree species were also calculated following Mueller-Dombois and Ellenberg (1974).

\subsubsection{Species richness}

Species richness is one of the most important elements in biodiversity, because the number of species existing at a site is a quantitative measure of biodiversity and allows comparison with other sites. The Jackknife method and Species Area Curve Estimates were applied to estimate the species richness in the 1-ha plot.

\section{The Jackknife method}

A non-parametric approach to estimate species richness is given by the formula:

$$
\hat{S}=s+\left(\frac{n-1}{n} k\right)
$$

where $\hat{S}=$ jackknife estimate of species richness.

$\mathrm{s}=$ observed total number of species present in $\mathrm{n}$ quadrats.

$\mathrm{n}=$ total number of quadrats samples

$\mathrm{k}=$ total number of unique species.

Unique species is defined as the species that occur in only one quadrat.

\section{Species area curve estimate}

Species Area Curve plots the area examined with cumulative sampling area (x-axis) versus the total number of species found in the quadrate samplings (y-axis). The curve determines whether species richness is increasing or has leveled off in the sample. The point at which the species are curve estimate levels off is the point where additional sampling is yielding no additional information about the number of species.

Another method of estimating species richness discussed by Krebbs (1999) is to extrapolate the species-area curve for the community. A regression line is fitted and used to predict the number of species on a plot or any particular size. This method is useful only for communities that have enough data to compute a species-area curve, and so it could not be used on sparsely sampled sites.

Preston (1962) suggested that the species-area curve is a log-log relationship of the form:

$$
\log (S)=a+\log (A)
$$

where $\quad S=\quad$ Number of species (= species richness)

$$
\begin{array}{ll}
\mathrm{A}= & \text { Area sampled } \\
\mathrm{a}= & \mathrm{y} \text {-intercept of the regression }
\end{array}
$$

\subsubsection{Species diversity}

Species diversity is the number of different species in a particular area (species richness) weighted by some measure of abundance such as number of individuals or biomass. The non-parametric measures of diversity proposed by this study are the Simpson's Index, the Shannon-Wiener Function and Brillouin's Index of Diversity. This index of diversity indicates the probability of picking two trees at random are different species. Higher values of the indices represent greater diversity.

Both Simpson's Index and the Shannon-Wiener Function indices are calculated using information about the proportion $\left(p_{i}\right)$ of individuals in the total sample $(N)$ that are represented by a given species $(i)$ such that:

\section{Simpson's index of diversity}

$$
p_{i}=\frac{n_{t}}{N}
$$

The Simpson's Index is given by

$$
D=\Sigma p_{t}^{2}
$$


where $\quad D=$ Simpson's index

$p_{i}=\quad$ Proportion of species $i$ in the community

This probability is converted into a measure of diversity by using the complement of Simpson's original measure:

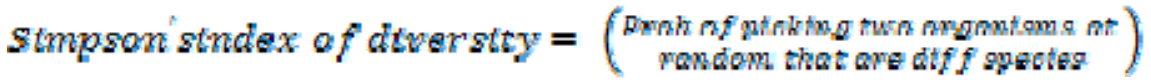

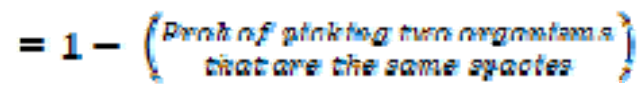

Thus,

where $\quad(1-D)=$ Simpson's index of diversity

$$
1-D-1-\Sigma\left(p_{t}\right)^{2}
$$

$p_{i} \quad=\quad$ Proportion of individuals of species $i$ in the community

Simpson's index $(1-D)$ ranges from 0 (low density) to almost $1(1-1 / s)$.

\section{Shannon-Wiener index of diversity}

Measures of species diversity can also be estimated based on information theory. This uncertainty can be measured by the Shahnon-Weiner function:

$$
H^{\prime}=\sum_{i=1}^{g}\left(p_{i}\right)\left(\log _{2} p_{i}\right)
$$

where $H^{\prime}=$ Information content of sample (bits/individual)

$$
=\text { Index of species diversity }
$$

$s \quad=\quad$ Number of species

$p_{i} \quad=\quad$ Proportion of total sample belonging to $i^{\text {th }}$ species

Information content is a measure of the amount of uncertainty, so that the larger the value of $H^{\prime}$, the greater the uncertainty. The Shannon-Weiner measures $H^{\prime}$ increases with the number of species in the community and in theory can reach very large values. In practice, for biological communities $H^{\prime}$ does not seem to exceed 5.0 (Washington 1984). The theoretical maximum value is $\log (\mathrm{S})$, and the minimum value (when $N>S$ ) is $\log [N /(N-S)]$ (Fager 1972).

\section{Brillouin's index of diversity}

In any case in which data are assume from a finite collection and sampling is done without replacement, the appropriate information-theoretic measure of diversity is Brillouin's formula:

$$
H=\frac{1}{N} \log \left(\frac{N !}{n_{2} ! m_{2} ! n_{2} ! \ldots}\right)
$$

where

$$
\begin{aligned}
\tilde{H} & =\text { Brillouin's index } \\
N & =\text { Total number of individuals in entire collection } \\
n_{1} & =\text { Number of individuals belonging to species } 1 \\
n_{2} & =\text { Number of individuals belonging to species } 2
\end{aligned}
$$

Any base of logarithm may be used. If base 2 logs are used, the units of $H$ are bits per individual. The Brillouin's index is like the Shannon function in being most sensitive to the abundance of rare species.

For further reading on heterogeneity measures see Krebbs (1999).

\subsubsection{Species evenness}

Another measure of species diversity is the species richness, which is the relative abundance with which each species is represented in an area. The Simpson's measure of evenness, Camargo's index of evenness and Smith and Wilson's index of evenness are discussed in this paper. Those indices are discussed in details in Krebbs (1999).

\section{Simpson's measure of evenness}

For Simpson's measure of heterogeneity, maximum diversity is obtained when all abundances are equal $(p=1 / S)$, so in a very large population:

$$
D_{M A Z}=\frac{1}{g}
$$


where

$$
\begin{array}{ll}
\mathbb{B}_{\text {MAX }} & =\text { Maximum possible value for Simpson's index (eq. [3]) } \\
s & =\text { Number of species in the sample }
\end{array}
$$

It is concluded from this formula that the maximum possible value of the reciprocal of Simpson's index $(1 / D)$ is always equal to the number of species observed in the sample. This leads to the definition of Simpson's index of evenness as:

$$
E_{1 / D}=\frac{1 / D}{g}
$$

where

$$
\begin{array}{lll}
E_{1 / \bar{E}} & =\text { Simpson's measure of evenness } \\
\widehat{D} & =\text { Simpson's index (eq. [3]) } \\
\mathrm{s} & =\text { Number of species in the sample }
\end{array}
$$

The index ranges from 0 to 1 and is relatively unaffected by the rare species in the sample.

\section{Camargo's index of evenness}

Camargo (1993) proposed an index of evenness that is unaffected by species richness:

$$
E^{\prime}=1.0-\left(\sum_{i=1}^{g} \sum_{i+i+1}^{g}\left[\frac{\eta_{i}-r_{l}}{a}\right]\right)
$$

where $\quad E^{\prime}=$ Camargo's index of evenness

$p_{i}=$ Proportion of species $i$ in total sample

$p_{j}=$ Proportion of species $j$ in total sample

$s=$ Number of species in total sample

This index, like Simpson's, is relatively unaffected by the rare species in the sample.

\section{Smith and Wilson's index of evenness}

Smith and Wilson (1996) proposed an index of evenness based on the variance in abundance of the species. The index is defined as:

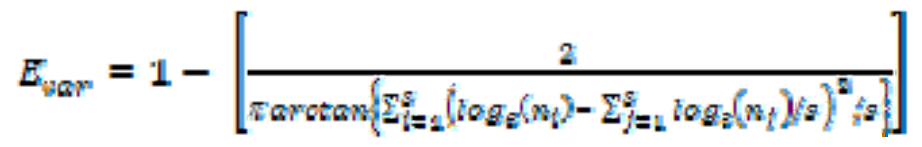

where $\quad E_{v a r}=$ Smith and Wilson's index of evenness

$n_{i} \quad=\quad$ Number of individuals in species $i$ in sample $(i=1,2, \quad \ldots, s)$

$n_{j} \quad=\quad$ Number of individuals in species $j$ in sample $(j=1,2, \quad \ldots, s)$

$s=$ Number of species in entire sample

According to Smith and Wilson, this is the best index of evenness because it is independent of species richness and is sensitive to both rare and common species in the community.

\section{Results and discussion}

(Note 1)

A total of 3414 individual trees representing 120 species, 81 genera and 31 families were recorded within the 1-ha study site. Species with highest relative abundance were Swintonia sp1 (0.12), Garcinia eugnifolia (0.09) and Syzygium sp1 (0.05). Fig. 1 shows the relative abundance of plant species in the 1-ha plot.

\subsection{Species richness}

The non-parametric Jackknife method was applied to estimate the species richness. Analysis was conducted using software (ECOMETH; http://www.ExeterSoftware.com).

(Note 2)

Result shows that the Jackknife estimator of species richness tends to overestimate the number of species observed in the 1-ha plot with an estimated number of 132.9 species. This study also discovered that there exist 13 unique species occurring, in only one quadrate (Table 1).

(Note 3)

Fig. 2 shows that the slope of the species area curve for the 1-ha study site declined as sample area increased but did not 
approach an asymptote. Using equation [2], the resulting regression equation is $\operatorname{Ln} \hat{S}=2.53+0.24 \ln (A)$ with $r^{2}=$ 96.01\%. The estimated linear regression line is also plotted in Fig. 2.

\subsection{Species diversity}

(Note 4)

Analysis using equation [4] indicated that Simpson's index of diversity was 0.96 , which suggests that diversity is high in the 1-ha plot. The Shannon-Weiner index of species diversity (equation [5]) was=5.61. This value exceeds the maximum value assumed for $H^{\prime}$ '(i.e. $\log S$ ), but this is not surprising since the forest area is highly diverse (referring to the result from Simpson's index of diversity). The estimate of the Brillouin's Index (equation [6]) was 5.50. These results are similar to those obtained by using Shannon-Weiner function (equation [5]). No decision has been made on which function is a better measure. In practice, this argument is irrelevant to field ecologist because both indices are almost identical for most ecological samples when $N$ is large (Krebbs 1999).

\subsection{Species evenness}

\section{(Note 5)}

Results showed that the Simpson's measure of evenness (equation [7]) was 0.219; while Smith and Wilson's index of evenness (equation [8]) based on the variance of abundance of the species was 0.325 . Similarly, Smith and Wilson's index of evenness (equation [9]) was estimated as 0.303. All the results suggest that evenness was low in the 1-ha plot at the Pasir Tengkorak Forest Reserve.

\subsection{Analysis of vegetation}

(Note 6)

Total density and basal area for the 10 most dominant species, were respectively 1812 trees ha ${ }^{-1}$ and $21.32 \mathrm{~m}^{2} \mathrm{ha}^{-1}$ in the 1-ha plot. Swintonia sp1 was found to be the most dominant with the highest IVI index (46.8) followed by Syzygium sp1 (36.3) and Garcinia eugnifolia (25.2) (Table 4).

(Note 7)

The distribution of dbh classes conformed to reverse ' $\mathrm{j}$ ' shape curve, with $86.5 \%$ of trees having dbh between $1-10 \mathrm{~cm}$, 305 trees $(8.9 \%$ ) having dbh between $>10-20 \mathrm{~cm}$, followed by $4.6 \%$ trees in the dbh class $>20-100 \mathrm{~cm}$. There were about 25 trees with a diameter greater than $50 \mathrm{~cm}$ (Table 5).

\section{Conclusion}

The non-parametric Jackknife method was applied to estimate the species richness. The diversity estimated using Simpson's index of diversity, Shannon-Weiner function and Brillouin index for the 1-ha plot was high and the evenness index was low ranging from $0.2-0.3$. The evenness is considered high when it varies near value of 1 . Although the two evenness measures result in different index of evenness, the Smith and Wilson's index of evenness is more preferred because it is independent of species richness and is sensitive to both and rare common species in the community (Krebs 1999).

The highest score for abundance rank was Swintonia sp1 (0.12), Garcinia eugnifolia (0.09) and Syzygium sp1 (0.05). These three species were the most common ones found in each subplot. The relative abundance functions as an estimate of diversity at one point in time and location or knowing what species are present at a given location. This is common way for diversity measure by measuring the number and relative abundance of species in an ecosystem (Gaines et al., 1999).

Anacardiaceae and Myrtaceae families were the most common species and widespread all over the country. However, Myrtaceae family was commonly found in the coastal beach, while Anacardiaceae was commonly found at the lowland forest. Myrtaceae has centers of diversity in Australia, Southeast Asia, and tropical to southern temperate America, but has little representation in Africa (Peter et al., 2001), so it is very common species in the coastal beach area and has relative highest abundance.

Both above-mentioned families showed the highest basal area, with $7.34 \mathrm{~m}^{2} \mathrm{ha}^{-1} 6.7534 \mathrm{~m}^{2} \mathrm{ha}^{-1}$, respectively, consisting most of the unmatured trees. Unmatured trees react as a regeneration part and may be viewed as an early indicator of forest recovery. It was shown that regeneration of the 1-ha plot was considerably high, with lack of supervision from local enforcement. The generation sapling will be degraded by human activities because Pasir Tengkorak Forest Reserve is well known as recreational forest.

\section{References}

Camargo, J. A. (1993). Must dominance increase with the number of subordinate species in competitive interactions? J.Theor. Biol., 161, 537-542.

Fager, E. W. (1972). Diversity: a sampling study. American Naturalist, 106, 293-310. 
Faridah Hanum, I., Ahmed Zainudin Ibrahim, Shamsul Khamis, M. Nazre, P. Lepun, G. Rusea, J.J. Lajuni \& A. Latiff. (2001a). An annotated checklist of higher plants in Ayer Hitam Forest Reserve, Puchong, Selangor. Pertanika Journal Tropical Agricultural Science, 24(1), 61-75.

Faridah Hanum, I., Rahim, A., Lepun, P., Edham, I., \& M. Nazre (2001b). Tree taxa inventory at Ayer Hitam Forest Base-Camp. Pertanika Journal Tropical Agricultural Science, 24(1), 29-34.

Gaines, W.L., Harrod, R.J. \& Lehmkuhl, F. (1999). Monitoring biodiversity: Quantification and interpretation. General technical report. PNW-GRT-443.

Krebs, C.J. (1999). Ecological Methodology. $2^{\text {nd }}$ edition. Addison Wesley Longman, New York.

Mueller-Dombois \& Ellenberg. (1974). Aims and methods of vegetation ecology. John Willey \& Sons, New York, 547p.

Peter G. W., Marcelle M. O'Brien, Paul A. G. \& Christopher J. Q. (2001). American Journal of Botany, 88, $2013-2025$.

Preston F. W. (1962). The canonical distribution of commonness and rarity. Ecology, 32, 074-104, 309-321.

Rusea, G., M.D. Bibian, W.K. Soh, Haja Maideen, M. Nazre \& I. Faridah Hanum. (2001). Notes on the herbaceous plants of Ayer Hitam Forest Reserve, Puchong, Selangor. Pertanika Journal Tropical Agricultural Science, 24(1), 35-38

Smith, B. \& Wilson, J. B. (1996). A consumer's guide to evenness indices. / Oikos, 76, 70-82.

Washington. (1984). H.G. Washington, Diversity, biotic and similarity indices. A review with special relevance to aquatic ecosystems. Water Res., 18, 653-694.

Table 1. Jackknife estimate of species richness

\begin{tabular}{|l|c|}
\hline Total number of species & 120 \\
\hline Jackknife estimates of species richness & 132.9 \\
\hline Standard deviation & 3.89 \\
\hline $95 \%$ confidence limit & 125.1 to 140.6 \\
\hline Number of unique species & 13 \\
\hline
\end{tabular}

Table 2. Diversity indices at the 1-ha plot at Pasir Tengkorak Forest Reserve.

\begin{tabular}{|l|c|}
\hline Measures of heterogeneity & Index \\
\hline Simpson's index of diversity & 0.962 \\
\hline Shannon-Wiener index of diversity & 5.607 \\
\hline Brillouin's index of diversity & 5.501 \\
\hline
\end{tabular}

Table 3. Evenness indices at the 1-ha plot at Pasir Tengkorak Forest Reserve.

\begin{tabular}{|l|l|}
\hline Measures of evenness & Index \\
\hline Simpson's measure of evenness & 0.219 \\
\hline Camargo's index of evenness & 0.325 \\
\hline Smith and Wilson's Index of Evenness & 0.303 \\
\hline
\end{tabular}


Table 4. Analysis of vegetation within the 1-ha plot at Pasir Tengkorak Forest Reserve.

\begin{tabular}{|c|c|c|c|c|c|c|c|c|}
\hline Species name & $\mathrm{D}\left(\right.$ tree ha $\left.{ }^{-1}\right)$ & $\mathrm{F}$ & BA & RD & RF & RBA (\%) & $\begin{array}{l}\text { Mean } \\
\text { HT (m) }\end{array}$ & IVI \\
\hline Swintonia spl & 411 & 83 & 7.34 & 12.04 & 10.63 & 24.13 & 7.32 & 46.80 \\
\hline Garcinia eugnifolia & 299 & 88 & 1.56 & 8.76 & 11.27 & 5.14 & 5.34 & 25.17 \\
\hline Syzygium sp.1 & 180 & 69 & 6.75 & 5.27 & 8.83 & 22.22 & 7.84 & 36.33 \\
\hline Barringtonia sp. & 149 & 62 & 0.36 & 4.36 & 7.94 & 1.19 & 5.41 & 13.49 \\
\hline Callophyllum sp1 & 124 & 40 & 0.76 & 3.63 & 5.12 & 2.49 & 6.35 & 11.24 \\
\hline Knema sp.1 & 124 & 57 & 0.45 & 3.63 & 7.30 & 1.47 & 4.80 & 12.40 \\
\hline Pentace sp. 1 & 111 & 52 & 1.92 & 3.25 & 6.66 & 6.30 & 7.35 & 16.21 \\
\hline Antidesma sp.1 & 90 & 35 & 0.15 & 2.64 & 4.48 & 0.49 & 4.18 & 7.61 \\
\hline Ardisia sp.1 & 87 & 45 & 0.12 & 2.55 & 5.76 & 0.39 & 4.27 & 8.70 \\
\hline Messua sp.1 & 85 & 61 & 1.08 & 2.49 & 7.81 & 3.56 & 6.89 & 13.86 \\
\hline Diosspyross sp. & 81 & 46 & 0.38 & 2.37 & 5.89 & 1.26 & 5.69 & 9.52 \\
\hline Memecylon sp.1 & 71 & 43 & 0.46 & 2.08 & 5.51 & 1.51 & 6.88 & 9.10 \\
\hline Others & 1602 & 100 & 9.07 & 46.92 & 12.80 & 29.84 & - & 89.57 \\
\hline Total & 3414 & 781 & 30.39 & 100 & 100 & 100 & & 300.0 \\
\hline
\end{tabular}

$\mathrm{D}=$ Density, $\mathrm{F}=$ Frequency, $\mathrm{BA}=$ Basal Area, $\mathrm{RD}=$ Relative Density, $\mathrm{RF}=$ Relative Frequency,

$\mathrm{RBA}=$ Relative Basal Area, IVI = Importance Value Index

Table 5. Distribution of different classes of trees and percentages of distribution.

\begin{tabular}{|c|c|c|}
\hline Dbh class $(\mathbf{c m})$ & No. of trees & $\%$ \\
\hline $1-10$ & 2954 & 86.53 \\
$>10-20$ & 305 & 8.93 \\
$>20-30$ & 99 & 2.90 \\
$>30-40$ & 22 & 0.64 \\
$>40-50$ & 9 & 0.26 \\
$>50-60$ & 17 & 0.50 \\
$>60-70$ & 2 & 0.06 \\
$>70-80$ & 1 & 0.03 \\
$>80-90$ & 3 & 0.09 \\
$>90-100$ & 2 & 0.06 \\
\hline Total & 3414 & 100 \\
\hline
\end{tabular}




\section{Heterogeneity}

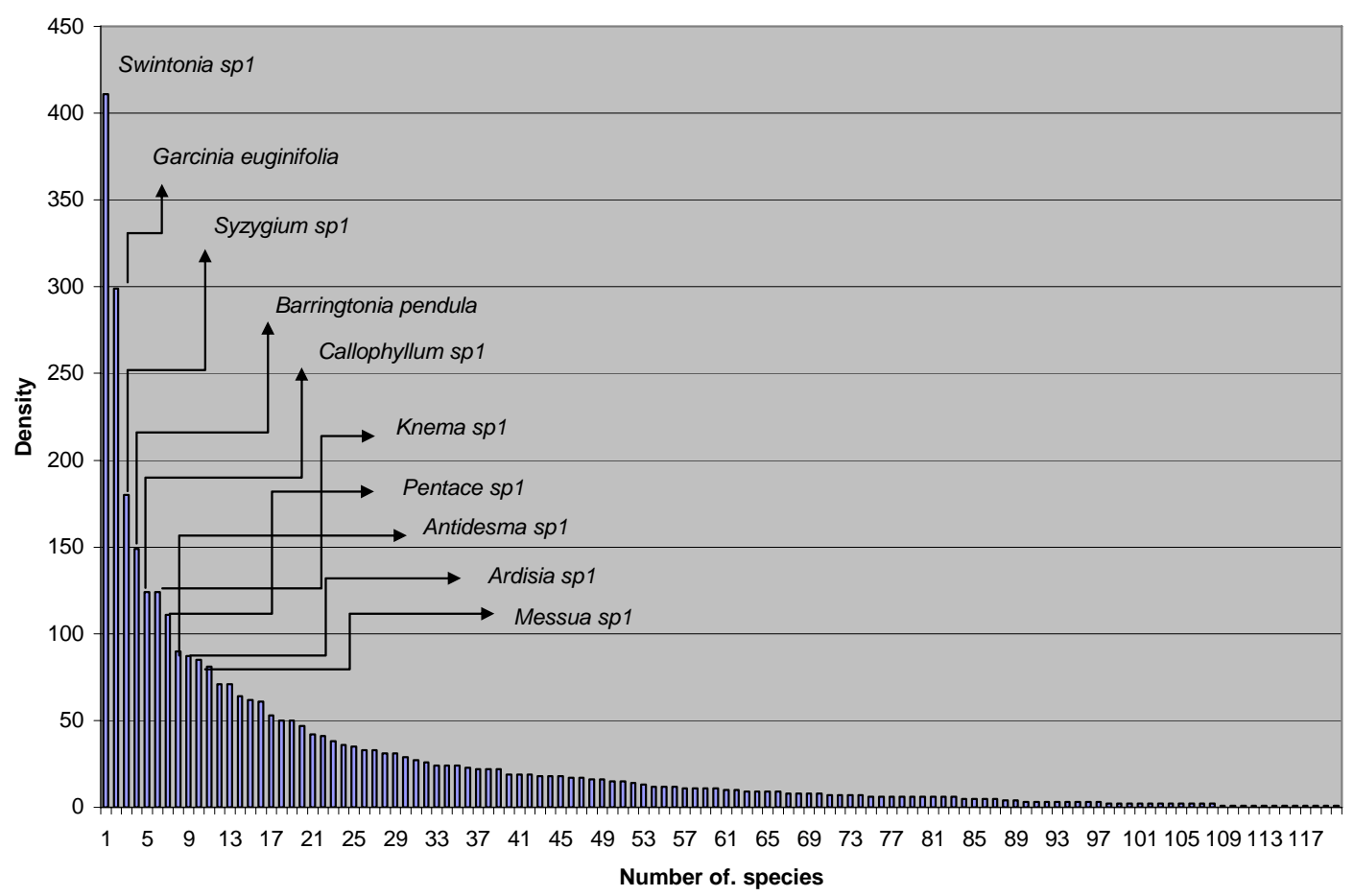

Figure 1. Heterogeneity in 1-ha plot at Pasir Tengkorak Forest Reserve

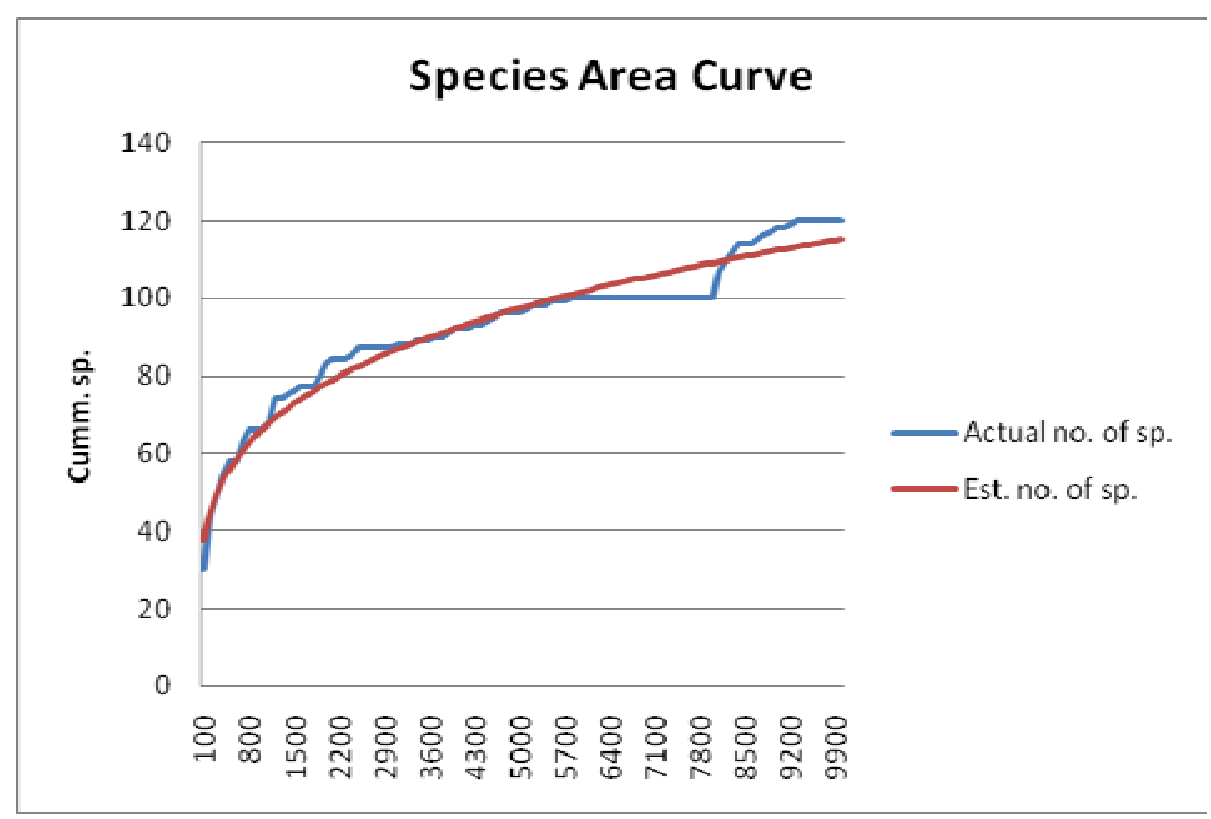

Figure 2. Species area curve estimate 